\title{
A utilização de softwares educacionais simuladores no ensino da física em uma escola pública estadual da cidade de Boa Vista/RR.
}

\author{
Angelo Augusto Coelho Freire, Estácio Atual, angelo.freire@estacio.br \\ Gracieth Mendes Valenzuela, Estácio Atual, gracieth.valenzuela@estacio.br \\ Hércules Gonçalves de Oliveira, Estácio Atual, Hercules.go@hotmail.com \\ Lenilson Menezes de Carvalho, Estácio Atual, lenilsonpark@hotmail.com \\ Ornélio Hinterholz Junior, Estácio Atual, ornelio.junior@estacio.br \\ Wender Antônio da Silva, Estácio Atual, UERR, wender.silva@estacio.br
}

Resumo. Este artigo apresenta uma pesquisa quantitativa de caráter exploratório acerca do uso de softwares educacionais simuladores como uma ferramenta de auxílio no processo de ensino-aprendizagem a partir de conteúdos curriculares da disciplina de Física com alunos do Ensino Médio. O estudo se deu na Escola Estadual Carlos Drummond de Andrade, com a experimentação de softwares educacionais simuladores, além da práticas de exercícios dirigidos e orientados pelo professor e pesquisadores que nortearam a resolução de situações problemas do ensino de Física juntos aos estudantes. Procurou-se com isso, avaliar quais as necessidades apresentadas pelos alunos para que ocorra o aumento dos níveis de rendimento escolar.

Palavras-chave: softwares educacionais, simuladores, física.

\section{The use of simulators educational software in teaching physics at a state public school of the city of Boa Vista / RR.}

\begin{abstract}
This article presents a quantitative exploratory research on the use of simulators as an educational software tool to aid in the process of teaching and learning from curriculum content of the discipline of physics in high school students. The study took place in the State School Carlos Drummond de Andrade, with the testing of educational software simulators, in addition to practical exercises directed and guided by the teacher and researchers who guided the resolution of problem situations in physics teaching students together. It sought to assess what needs presented by students for the increased levels of school performance occurs.
\end{abstract}

Keywords: educational software, simulators, learning physics.

\section{Introdução}

Fiolhais e Trindade (2003) afirmam tratar-se de um assunto que já não é mais discutível a importância do papel exercido no ambiente escolar pela tecnologia; entretanto, a metodologia que se deve utilizar ainda é uma questão levantada pelos profissionais em educação devido ao grande número de softwares e aplicativos que se oferecem e disponibilizam nas instituições públicas educacionais, por meio de programas de incentivo às tecnologias, como o Programa Nacional de Tecnologia Educacional PROINFO. Desta forma, a presente pesquisa se justifica pela existência da necessidade de se analisar a viabilidade da implementação e utilização de softwares livres de 
simulação nos ambientes de laboratórios de Informática em favor do processo de ensino e aprendizagem, mais especificamente para a disciplina de física nas escolas públicas estaduais do município de Boa Vista, tendo como amostragem do estudo alunos da Escola Estadual Carlos Drummond de Andrade, objetivando a disponibilidade de seus laboratórios, sua conexão à internet e ainda, as dificuldades encontradas diante dos conteúdos programáticos da disciplina de física pelos discentes.

A problemática deste estudo se originou de um questionamento: É viável a utilização de softwares simuladores educacionais para o ensino da disciplina de física nas escolas públicas no município de Boa Vista? Buscou-se então uma resposta para o problema apresentado junto à literatura, por meio dos autores como Freire (1996), Valente (1998) e Fiolhais e Trindade (2003). Também procurou-se levantar informações por meio de manuais e cartilhas oficiais do Governo como os Indicadores de Qualidade na Educação e o Guia de recomendações para a Montagem de Laboratório de Física (2012), além de realizar um embasamento normativo por meio das diretrizes dadas pelos Parâmetros Curriculares Nacionais - PCNs.

De posse das informações levantadas, objetivou-se realizar um estudo de viabilidade sobre a utilização de um grupo de softwares simuladores no ensino da disciplina de física nas séries iniciais do Ensino Médio. Além disso, outros objetivos secundários também foram trabalhados durante o processo de elaboração e pesquisa deste trabalho, como o estudo do plano anual de ensino de física do $1^{\circ}$ ano do ensino médio, relacionando os principais assuntos trabalhados na disciplina em questão; A identificação dos conteúdos da disciplina de física que apresentam maiores dificuldades para que com base nas dificuldades encontradas, escolher os softwares que deveriam ser utilizados na pesquisa e na aplicação com os alunos por meio de simulação com a resolução de problemas. Neste sentido, após identificar o conteúdo, foi realizado a elaboração de um plano de aula que contemplasse tal conteúdo na utilização de softwares simuladores.

Após a aplicação da simulação, pode-se realizar, com a colaboração do professor da disciplina de física, um estudo comparativo entre duas turmas quanto ao entendimento do conteúdo e ao rendimento em termos de notas antes e depois da aplicação dos softwares em aula, podendo com isso, elaborar um coeficiente de diferenciação das turmas. Assim, através de experimentação por meio da aplicação dos softwares simuladores aos estudantes, pode-se entender que o conhecimento se constrói de maneira mais ampla e simplificada quando apoiado pela prática. Coloca-se esta reflexão porque chegou-se a resultados de melhoria nas atividades avaliativas da turma onde se realizou a pesquisa de aplicação dos softwares de simulação. Os estudantes tiveram a oportunidade de experimentar na prática o que conheciam somente na teoria, ampliando possibilidades de se questionarem quanto aos fatos e a melhor solução para os problemas lançados pelo professor em aula.

\section{Ensino da física}

O ensino de física nas escolas brasileiras vem recebendo, há anos, críticas por não se realizar atividades experimentais; o único recurso do professor, tem sido ,saliva e giz ${ }^{\text {ee }}$. Gaspar (2003) ressalta ainda que, ao aluno cabe apenas ouvir, copiar e memorizar. Essa prática nada contribui para um ensino eficaz da ciência física na qual se insere a física moderna e contemporânea: o ensino deve estimular ideias, permitindo aos alunos pensar 
e interpretar o mundo que os cerca. O cotidiano vivenciado pelos estudantes é fundamental na definição da forma de abordagem dos conteúdos previamente definidos como relevantes. Nesse contexto, atividades experimentais ganham importância. Ainda de acordo com os PCNs (1998), a física é um conhecimento que possibilita a elaboração de modelos da evolução cósmica, além de oferecer meios de investigação de "mistérios de um mundo submicroscópico", das partículas que compõem a matéria, e favorece a descoberta de novas fontes de energia, criação de produtos e novos materiais tecnológicos. Deve ainda ser incorporada à cultura como instrumento de tecnologia, e pontuado como um conhecimento essencial para a construção da cidadania da humanidade.

\section{Física no ensino médio}

Fiolhais e Trindade (2003) afirmam que o $1^{\circ}$ ano do ensino médio representa um período de grandes mudanças na vida escolar dos alunos. Nele, são introduzidos os ensinos de física, química e biologia de forma separada, cartesiana, de modo que os alunos compreendam as ciências exatas de forma mais ampla e complexa. Nesse contexto, a física tem se destacado como a disciplina em que os alunos enfrentam maiores dificuldades de aprendizagem, quer seja pela metodologia predominantemente teórica adotada pelos educadores, quer seja pela falta de recursos pedagógicos capazes de demonstrar na prática os fenômenos abordados, resultando no aumento de rendimentos insatisfatórios nessa disciplina pelos alunos.

Silva (2013) discorre sobre o ensino da física no ensino médio apontando que esta deve ser trabalhada de maneira que mostre aos estudantes as similaridades da matéria (conteúdo) com as experiências vividas no dia-a-dia. Segundo ele, relacionar matérias, levar experimentos para o ambiente da sala de aula, mostrar na prática como funcionam as teorias, faz com que o aluno se motive e desenvolva gosto pela disciplina que estuda. Ainda de acordo com Fiolhais e Trindade (2003), a grande dificuldade enfrentada pelos docentes no ensino da física está relacionada à inexistência de recursos pedagógicos modernos e inovadores, capazes de despertar o interesse dos alunos pelos fenômenos físicos e que possibilitem a aplicação dos conceitos teóricos na prática cotidiana. Assim, o avanço do uso do computador na sala de aula surge como uma esperança de mudança, principalmente para a facilitação do ensino, de modo a tornar possível uma aprendizagem efetiva.

\subsection{Laboratório de física}

Conceituados por Bazin e Lucio (1981), os laboratórios de física se constituem como valioso instrumento de aprendizado de fenômenos da natureza, como uma futura possibilidade de novas descobertas, abrindo espaço ainda para propiciar a aquisição de novos conceitos e reformulação dos mesmos, sendo indispensável sua utilização. $O$ importante do laboratório de física é possibilitar a construção de novos modelos que expliquem novos fenômenos, pois, afirmam que utilizando o plano de fundo cultural, pode-se ressaltar que em muitos casos a física foi elaborada a partir de situações de problema que eram de interesse para a sociedade num determinado contexto histórico. Generalizando, Moreira (1994) diz que muitas escolas e professores já reconhecem a importância das atividades experimentais, porém, a relação aos que se limitam ao giz e quadro-negro, ainda é muito pequena. 


\section{Aprendizagem baseada em problemas}

Freire (1999) afirma que o educador precisa saber que ensinar não é transferir conhecimento, mas criar as possibilidades para a sua produção ou a sua construção. Tal afirmativa é contraditória ao método tradicionalmente imposto pelas escolas, onde o mestre, por meio da sua experiência em áreas especificas, transmite esse saber em aulas expositivas e pouco interativas. Lollini (1991), ressalta que uma das vantagens do uso do computador no campo da educação é, a de tentar resolver um dos graves problemas da educação: encontrar um meio de respeitar o ritmo da aprendizagem, evitando defasagens entre os tempos da escola e o tempo necessário ao estudante numa atividade particular em um determinado momento da vida. Segundo Gil (2006), a aprendizagem que baseia-se em problemas (ABP) é a estratégia na qual os estudantes trabalham com o objetivo de resolver problemas por meio de estudos de caso previamente montados.

Por meio deste método, de acordo com Spaulding (1969), o estudante muda de papel no processo de aprendizagem, evoluindo de receptor passivo para ativo, responsável pelo seu aprendizado. Vale ressaltar que a responsabilidade individual aumenta quando se opta pela utilização desse método para que as metas educacionais sejam efetivadas e a construção do conhecimento contemplada.

\section{Softwares educacionais simuladores}

De acordo com Lucena citado por Teixeira e Brandão (2003), um Software Educacional (SE) diz respeito a todo o software que tenha finalidade ou propósito de ser utilizado na área educacional, pedagogicamente defensável, por professores e alunos, qualquer que seja o objetivo para o qual tenha sido criado. Outra linha de pensamento é a de Gamez (1998) onde afirma que o objetivo de um Software Educacional é o auxílio ao processo de ensino aprendizagem de uma determinada disciplina. Para tanto, o software deve possuir uma série de características, como a facilidade quanto ao uso e entendimento, além de favorecer a assimilação dos conteúdos programáticos motivando e ganhando o interesse dos estudantes, bem como avaliando e nivelando seus conhecimentos e pontuando suas dificuldades para que o professor possa saná-las posteriormente. Os SE apresentam uma classificação quanto ao nível educacional a saber: Sequencial: onde o aluno memoriza o conteúdo exposto e, quando solicitado o repete, agindo como sujeito passivo; Relacional: favorece a aquisição de habilidades pelo estudante, possibilitando que o mesmo relacione o que aprendeu a outras experiências e fatos, sendo assim considerada uma relação homem/máquina o que isola o aluno. Criativo: onde o aluno tem a possibilidade de criar uma interação entre a pessoa e a tecnologia, em um aprendizado participativo.

Valente (1998) destaca ser possível a simulação de um fenômeno no computador utilizando somente a implementação de um modelo desse fenômeno. Ainda afirma que a diferença entre software de simulação em relação a um software de modelagem é que no segundo o aprendiz além de escolher o modelo, o desenvolve e o implementa, enquanto no software de simulação ele recebe um modelo já acabado.

\subsection{Softwares simuladores de física}

Fiolhais e Trindade (2003) relatam que o uso de simuladores é um dos instrumentos mais populares de aprendizagem da física nos ambientes escolares que já utilizam as novas tecnologias. Ao utilizar esses softwares, cabem aos alunos a alteração dos valores 
das variáveis e a observação das alterações nos resultados após a proposição de parâmetros diferentes. Ainda, segundo Fiolhais e Trindade (2003) o uso de simuladores pode possibilitar o esclarecimento de questionamentos até então considerados de difícil resolução pelos alunos, devido à dificuldade de demonstração das teorias na prática.

Entre os vários ambientes on-line que oferecem simuladores educativos livres, destacamos a Universidade do Colorado, que possui um grande repositório de objetos de aprendizagem, o PhET - Interactive Simulations ${ }^{1}$, que possui vários jogos simuladores para diversas disciplinas do ensino fundamental e médio.

\section{Propostas pedagógicas utilizando as TIC’s}

De acordo com Mendes (2006), os jogos de computador e simulações vem sendo empregados cada vez mais em todas as áreas da educação, em especial na disciplina de física. Mendes (2006) ainda afirma que as simulações e jogos, usando computadores ou não, são ferramentas poderosas quando usadas adequadamente e no lugar certo, podendo contribuir muito para que a aprendizagem seja mais prazerosa. Para Oliveira (2005), as Novas Tecnologias de Informação e Comunicação (NTIC ${ }^{\text {ee }}$ ) estão derrubando as paredes das salas de aula das escolas e universidades atuais, fazendo com que professores e alunos ingressem no espaço virtual. Para ele, o jovem aluno não procura mais o conhecimento bem estruturado e de fácil acesso nos livros didáticos, e sim no imenso universo do hipertexto. Assim, frente a essa realidade, o aluno tem que reaprender a estudar e o professor a ensinar.

\section{Metodologia da pesquisa}

Para a aplicação da pesquisa, foram selecionadas duas turmas do $1^{\circ}$ ano do ensino médio, uma turma controle e outra turma experimento, ambas com o mesmo professor regente na disciplina de física. Primeiramente utilizou a observação participante, de forma a se estabelecer as principais dificuldades encontradas no processo de ensino e aprendizagem desta disciplina, por meio de análises de exercícios, provas e trabalhos escolares realizados em sala de aula pelos estudantes. Após diagnosticada a principal dificuldade em termos de aprendizagem no conteúdo, definiu-se a turma experimento e a turma controle à aplicação do conjunto de softwares simuladores educacionais. Aplicou-se softwares simuladores para cada conteúdo onde diagnosticou-se dificuldades de aprendizagem e, desta forma foram elencados e aplicados vários softwares aos alunos por meio da resolução de problemas na área da física.

Desta forma, este estudo trabalhou com a abordagem quantitativa de cunho experimental uma vez que para realizá-lo, foram necessárias, além de pesquisas na literatura, a experimentação de um software específico em alunos da $1^{\text {a }}$ série $\mathrm{D}$ do Ensino Médio da Escola Estadual Carlos Drummond de Andrade, coordenado pelo professor regente da disciplina de física, objetivando a melhoria do rendimento em termos de notas dessa disciplina. Para fortalecer o referencial teórico utilizado neste estudo, foram realizados estudos de vários autores relacionados ao tema, de modo a embasarmos o trabalho de acordo com a necessidade da área da pesquisa.

\footnotetext{
${ }^{1}$ https://phet.colorado.edu/pt_BR/simulations/category/html
} 
Tabela 1. Descrição dos softwares simuladores aplicados durante a pesquisa de campo

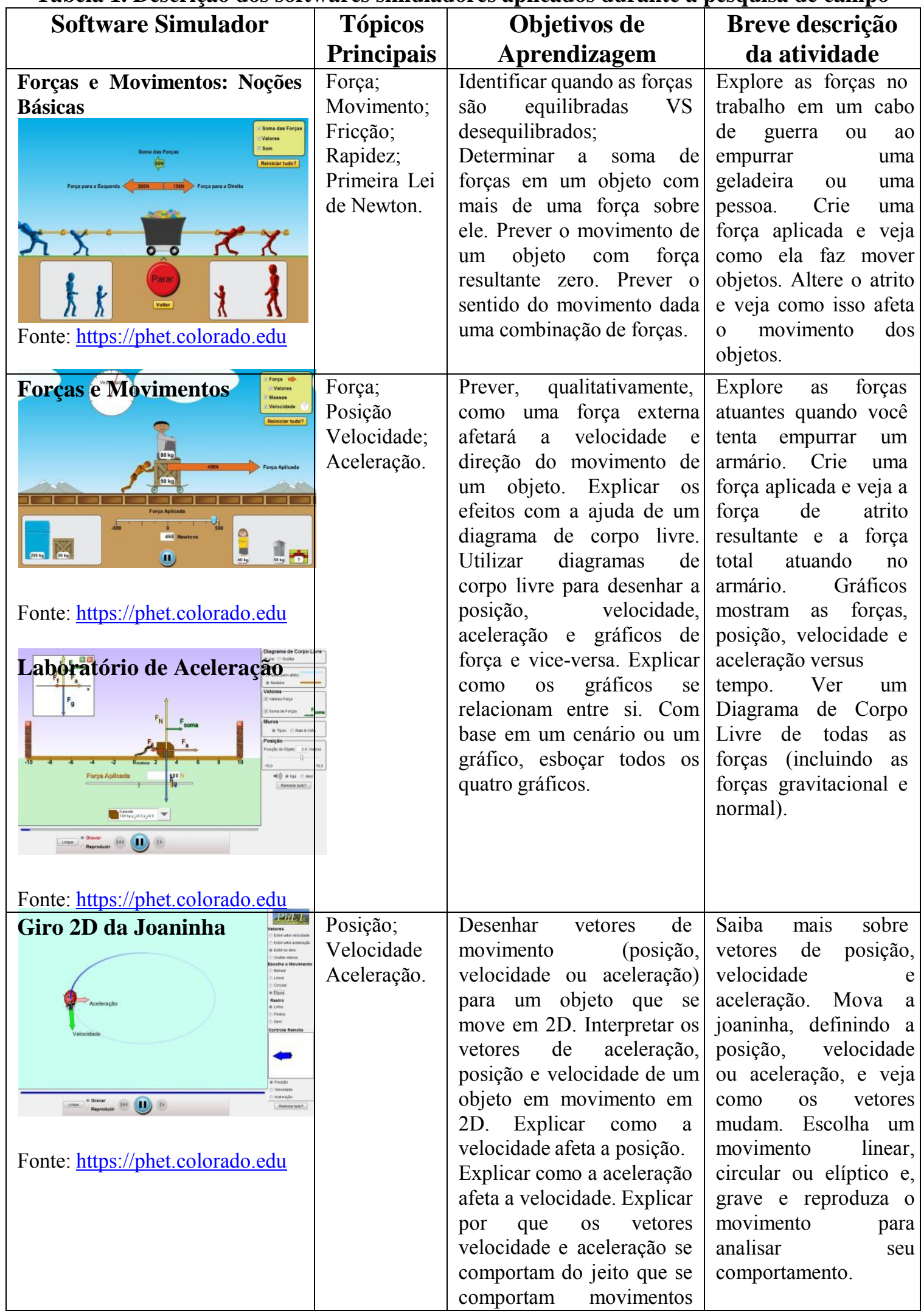




\begin{tabular}{|c|c|c|c|}
\hline & & linear, circular e elíptico. & \\
\hline $\begin{array}{l}\text { O Homem em Movimento. } \\
\text { Fonte: https://phet.colorado.edu }\end{array}$ & $\begin{array}{l}\text { Posição; } \\
\text { Velocidade; } \\
\text { Aceleração. }\end{array}$ & $\begin{array}{l}\text { Interpretar, prever e } \\
\text { desenhar gráficos (posição, } \\
\text { velocidade e aceleração) } \\
\text { para situações comuns. } \\
\text { Descrever seu raciocínio } \\
\text { para entender os gráficos. }\end{array}$ & $\begin{array}{l}\text { Saiba mais sobre } \\
\text { gráficos de posição, } \\
\text { velocidade } \\
\text { aceleração. Mova o } \\
\text { homenzinho para lá e } \\
\text { para cá com o mouse e } \\
\text { trace o seu } \\
\text { movimento. Defina a } \\
\text { posição, velocidade, } \\
\text { ou aceleração e deixe } \\
\text { a simulação mover o } \\
\text { homem para você. }\end{array}$ \\
\hline Fonte: $\underline{\text { https:/phet.colorado.edu }}$ & $\begin{array}{l}\text { Força; } \\
\text { Posição; } \\
\text { Velocidade; } \\
\text { Aceleração }\end{array}$ & $\begin{array}{l}\text { Prever, qualitativamente, } \\
\text { como uma força externa } \\
\text { afetará a velocidade e } \\
\text { direção do movimento de } \\
\text { um objeto. } \\
\text { Explicar os efeitos com a } \\
\text { ajuda de um ar aver de } \\
\text { corpo livre. } \\
\text { Utilizar diagramas de } \\
\text { corpo livre para desenhar a } \\
\text { posição, velocidade, } \\
\text { aceleração e gráficos de } \\
\text { força e vice-versa. } \\
\text { Explicar como os gráficos } \\
\text { se relacionam entre si. } \\
\text { Com base em um cenário } \\
\text { ou um gráfico, esboçar } \\
\text { todos os ar av gráficos. }\end{array}$ & 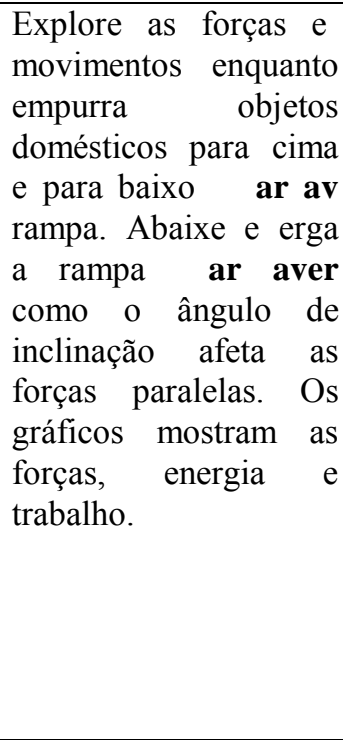 \\
\hline $\begin{array}{l}\text { Movimento retilíneo uniforme. } \\
\hat{\nabla} v \hat{v}\end{array}$ & $\begin{array}{l}\text { Mecânica; } \\
\text { Movimento. }\end{array}$ & $\begin{array}{l}\text { Prever, qualitativamente, a } \\
\text { diferença de velocidade } \\
\text { entre dois pontos distintos } \\
\text { em situações comuns. }\end{array}$ & $\begin{array}{l}\text { Saiba mais sobre } \\
\text { aceleração usando } \\
\text { dois automóveis, } \\
\text { definindo a velocidade } \\
\text { de cada automóvel, e } \\
\text { percebendo o percurso } \\
\text { de cada um deles. }\end{array}$ \\
\hline
\end{tabular}

Após a aplicação dos softwares em sala de aula, aplicou-se questionário, com o intuito de extrair do professor as principais dificuldades enfrentadas por ele no processo de ensino e aprendizagem da disciplina de física.

Desta forma, Gama (1993) relata que a avaliação pode ser entendida como um processo de julgamento que se vale de meios objetivos e subjetivos para atribuir valores àqueles que participam dele interativamente com a finalidade de superação do estágio de aprendizagem em que se encontram. Assim, para a avaliação, o professor aplicou um exercício avaliativo, usando sua própria metodologia de ensino, sobre os assuntos

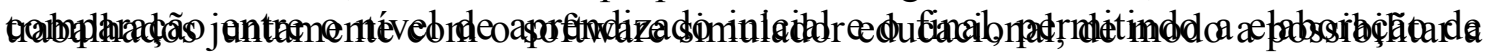


um coeficiente de diferenciação entre as turmas antes e depois da aplicação desta pesquisa. De acordo com Barros e Lehfeld (2004), na maioria das vezes as pesquisas são realizadas por meio de amostras, pois a observação completa de um fenômeno envolve um volume muito grande de dados, o que dificulta e prolonga a análise.

\section{Desenvolvimento da pesquisa}

Quanto aos procedimentos adotados, inicialmente houve uma conversa com a turma explicando o propósito do estudo. Posteriormente, o professor regente auxiliou na formação dos grupos de alunos e pode-se então, explicar como se daria a atividade em sala, com os simuladores nos notebooks.

Cada grupo recebeu um notebook com os simuladores acima citados, e pode, sob a orientação do professor, simular a resolução de problemas, com a finalidade de entender o conteúdo já ministrado em aulas anteriores para um futuro comparativo de melhoria nas notas da turma em relação a outra turma do mesmo ano, da mesma escola, com o mesmo professor ministrando conteúdos igualmente semelhantes. $\mathrm{O}$ quadro comparativo se deu com relação aos alunos do $1^{\circ}$ ano $\mathrm{D}$ (turma onde foram aplicadas as atividades de simulação com os softwares) e a turma do $1^{\circ}$ ano B (onde não se aplicaram as atividades). $\mathrm{O}$ quadro a seguir ilustra as médias de notas de um trabalho aplicado no $1^{\circ}$ bimestre nas duas turmas, na disciplina de física, antes da aplicação dos simuladores. Note-se que o valor do trabalho era de 12 pontos.

Tabela 2. Médias das notas do $1^{0}$ trabalho de física nas turmas pesquisadas

\begin{tabular}{|c|c|}
\hline \multicolumn{2}{|c|}{ Média das notas do trabalho de valor 12 pontos } \\
\hline $1^{\mathrm{o}}$ ano B (20 alunos) & $1^{\mathrm{o}}$ ano D (23 alunos) \\
\hline 7,5 & 6,5 \\
\hline
\end{tabular}

Após a aplicação dos softwares simuladores com os alunos do $1^{\circ}$ ano $\mathrm{D}$, foi proposto às duas turmas mais um trabalho, dentro do mesmo conteúdo, ainda no $1^{\circ}$ Bimestre, e com o valor avaliativo de 12 pontos. Observa-se no quadro abaixo, as mudanças que ocorreram em função da aprendizagem prática proporcionada pelos softwares simuladores.

Tabela 3. Médias das notas do $2^{\mathrm{a}}$ trabalho de Física nas turmas pesquisadas

\begin{tabular}{|c|c|}
\hline \multicolumn{2}{|c|}{ Média das notas do trabalho de valor 12 pontos } \\
\hline $1^{\mathrm{o}}$ ano B (20 alunos) & $1^{\mathrm{o}}$ ano D (23 alunos) \\
\hline 8,0 & 9,5 \\
\hline
\end{tabular}

Percebe-se com isso, que os alunos da turma B não alcançaram uma grande evolução nas notas referentes aos dois trabalhos feitos. Em contrapartida, os alunos da turma D, que receberam a oportunidade de conhecer, manusear e praticar o conteúdo ministrado por meio dos softwares simuladores apresentaram uma visível melhora nas notas referentes aos trabalhos aplicados em aula. Isso se dá porque a prática de um conteúdo teórico o torna mais fácil de ser entendido e assim, abre caminho para a construção do 
Simuladores (SL) pode contribuir com a educação, apresentando benefícios em relação a outros tipos de software, tais como: maior interatividade, novas formas de visualização de informações, envolvimento, melhor compreensão do objeto de estudo, entre outros. Valente (1998) afirma que o computador pode ser um importante recurso para promover a passagem de informação ao usuário ou para promover a aprendizagem. No entanto, da análise dos softwares, é possível entender que o aprender não deve estar restrito ao uso deles, mas deve estar restrito à interação professor-aluno-software. Alguns deles apresentam características que favorecem à atuação do professor, como no caso da programação; outros, em que certas características não estão presentes, requerem um maior envolvimento do professor para auxiliar o aluno a aprender, como no caso do tutorial.

Para melhor ilustrar o trabalho, apresenta-se na figura 1, alguns alunos realizando estudos com a utilização dos computadores por meio dos simuladores. E importante destacar que as escolas não possuem laboratórios de Informática com muitos computadores e muitos laboratórios encontram-se desativados devido a falta de manutenção e, desta forma, inibe e prejudice o acesso para os estudantes aos recursos que a escola poderia disponibilizar para seu melhor aprendizado.

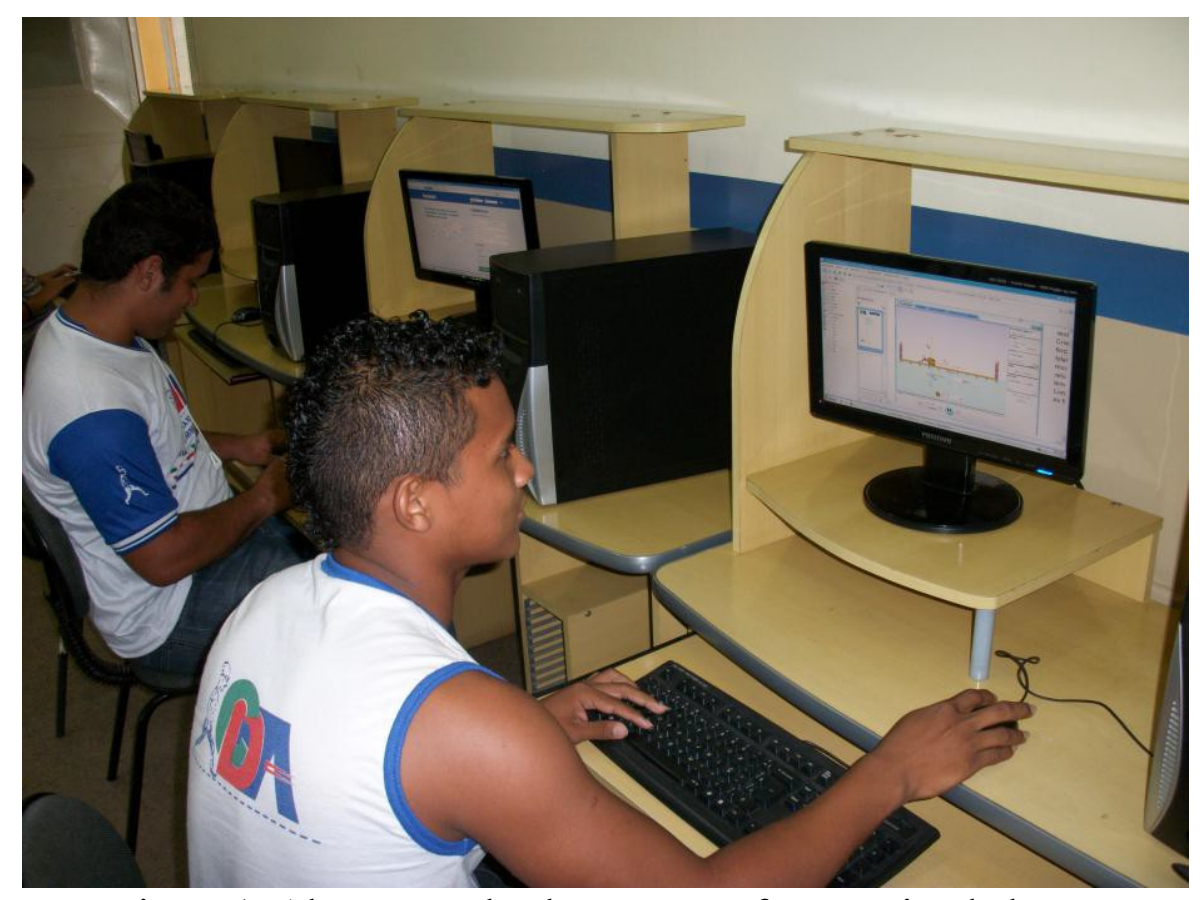

Figura 1: Alunos estudando com os softwares simuladores.

\section{Considerações}

Esta pesquisa tratou-se de uma experiência em que teve-se a oportunidade de verificar como ocorre o processo de aprendizagem pela prática e mais ainda como o software simulador educacional pode contribuir nesse processo de aquisição de conhecimento.

Porém, percebeu-se que ainda existem muitas dificuldades quando se trata de educação nas escolas da rede pública estadual roraimense, especialmente no município de Boa Vista. Há muitos fatores que impedem que o processo de ensino-aprendizagem ocorra 
em sua totalidade. Mais uma vez foram presenciadas várias dificuldades dentro da escola, bem como falta de manutenção nas estruturas físicas, entre outras de caráter burocrático como a falta de professores e funcionários capacitados adequadamente para seus cargos e funções.

É preciso repensar no conceito de Educação no estado de Roraima, pois são muitas as dificuldades encontradas dentro das escolas. Muitas barreiras impedem que uma educação de qualidade chegue ao seu destino final, os discentes.

Assim, cabe a sociedade cobrar de seus governantes um maior cuidado, uma maior atenção à educação como um todo, não privilegiando apenas uma área e sim contemplando a construção do conhecimento de maneira global, em função da formação de cidadãos capazes de conduzir uma sociedade evoluída tecnológica e culturalmente.

\section{Referências Bibliográficas}

FIOLHAIS, Carlos; TRINDADE, Jorge. Física no computador: o computador como uma ferramenta no ensino e na aprendizagem das ciências físicas. In: Revista Brasileira de Ensino de Física. Vol.25 número 3. São Paulo: Setembro/2003.

FREIRE, Paulo. Pedagogia da autonomia: saberes necessários à prática educativa. Rio de Janeiro: Paz e Terra, 1999.

GIL, A. C. Didática do ensino superior. São Paulo: Atlas, 2006.

VALENTE, J. A. Análise dos diferentes tipos de software usados na Educação. In: Salto para o Futuro: TV e Informática na Educação. MEC, Secretaria de Educação a Distância, Brasília, 1998.

BRASIL. MEC. SEF. Parâmetros curriculares Nacionais, 1998.

SILVA, M. A. Física: Estratégias de Ensino. Educador - Brasil Escola 2013. Equipe Brasil Escola.

BAZIN, M e P. Lucio. Por Que e Como Estudar o Pêndulo Simples no Laboratório Físico? Rev. Bras. Ens. Fis., vol 3, 1981.

LOLLINI, P. Didática e computadores: quando e como a informática na escola. São Paulo: Loyola, 1991.

GIL, A. C. Métodos e técnicas de pesquisa social. São Paulo: Atlas, 2006.

TEIXEIRA, A. C.; BRANDÃO, E.J.R. Software educacional: difícil começo. In: revista novas tecnologias na educação - Renote. Vol 1. $\mathrm{n}^{\circ}$ 1. CINTED/UFRGS, fev/2003.

GAMEZ, Luciano. TICESE-Técnica de inspeção de conformidade ergonômica de

Software educacional. Dissertação de Mestrado submetida à Universidade do Minho. Portugal. 1998.

MENDES, C. L. Jogos eletrônicos: diversão, poder e subjetivação. Campinas-SP: Papirus, 2006.

BARROS, A. J. P.; LEHFELD, N.A.S. Projeto de Pesquisa: Propostas metodológicas. Petrópolis/RJ: Vozes, 2004. 